\title{
Strategic Agility in Environmental Turbulence A case of Banking Sector in Indonesia
}

\author{
Winda Anggraini ${ }^{1}$ and Lily Sudhartio ${ }^{2}$ \\ Faculty of Economic and Business, University of Indonesia ${ }^{1,2}$ \\ windaanggraini.hrp@gmail.com ${ }^{1}$, lily.sudhartio@gmail.com²
}

\begin{abstract}
Adapting to environmental turbulence is mandatory for every player in the banking sector. They need to develop rational strategies and respond effectively. Environmental Turbulence especially market turbulence and technological turbulence, which happen lately in banking industry, require firms to review their strategies continuously. Strategic agility with its dimensions: strategic sensitivity, resource fluidity, and collective commitment, is a capability of a firm that has been identified as a key to succeed in a highly competitive and rapidly changing environment. Strategic agility is also known as a source of competitive advantage which will also enhance performance of the firm. This study tries to examine strategic agility and its dimension and reveal its importance in the banking sector in order to gain competitive advantage in environmental turbulence. Furthermore, this study explores the application of strategic agility and its potential to improve unit performance through competitive advantage. The population of this study is managers in one of private bank in Indonesia. This study uses Structural Equation Modelling (PLSSEM) to analyze the data. Findings of this study suggest that strategic agility has a role to gain competitive advantage by taking advantages from environmental turbulence specifically in market and technological turbulence which in turn will also improve firm performance.
\end{abstract}

Keywords: Strategic Agility, Environmental Turbulence, Competitive Advantage, Performance.

\section{Introduction}

Competition in the era of globalization is a huge challenge for companies but it also can be an opportunity. Companies are required to have a strategy to improve their position in this tight competition. Even for organizations at its peak of its life cycle that is at its mature stage still require to continue innovating. Moreover, technological innovation, and rapid change of customer preference requires high interaction between company and the customer.

In today's business environment, organization need to actively observe every opportunities and challenge to be able to survive or even become the leader in the competition. Fundamental changes in technology, market conditions, and customer demand create a fastchanging and uncertain environment. To deal with this, many companies try to differentiate by adopting different procedures and instruments to improve their organization competitive position.

In the latest market conditions, organizations are faced with a variety of changes that often occur simultaneously and unpredictable which forces organizations to revise their work 
methods continuously in order to adapt quickly. In this context, strategic flexibility known as strategic agility shows the ability of an organization to manage market change through rapid proactive responses to threats and market opportunities [1]. Dreyerand and Gronhaug (2004) mention the importance of increasing strategic agility as a source of excellence in competitive markets in recent years [2]. Therefore, in a turbulent environment, one of the important features of organization's key success factors is strategic agility.

Many businesses are not sure how to deal with turbulent environments. They believe that identifying the causative relationship between environmental variables and actions taken by the management team can help to overcome this dynamic situation. Organizations shape their environment by influencing their industry or collaborating with each other, thereby gaining control of some parts of their environment. Such environment are not fully determined by external forces, but is also influenced by the company itself.

Building strategic agility in the era of dynamic environment is currently a challenge for banks in Indonesia. Even some bank in Indonesia cannot maintain their strategic agility so they need to merge with the other or be acquired. Therefore, organizations need to continue to give more attention to their strategic agility as dynamic capabilities through proper performance appraisal.

With this increasing competition in the Indonesian banking system, each bank tries to make various ways to increase or at least maintain their market share. Banks are supported by their competitive advantage to strengthen their position and guarantee their success in competition. Change of customer preferences and rapid development of technology greatly influences the banking business. This environmental turbulence faced by bank makes banking as one of the industry that need strategic agility the most.

The purpose of this study is to empirically investigate the mediation of competitive advantage [3] on the relationship between strategic agility [4] in order to achieve organizational performance in the environmental turbulence [3]. The context of this study is bank in Indonesia.

\section{Literature Review}

This section will discuss about the variables which consist of: strategic agility; competitive advantage, environmental turbulence, and performance.

2.1 Strategic Agility

Strategic agility is defined as organization's ability to ensure itself to be flexible to adapt in any environmental condition [4], as well as the organization's ability to continually adjust their strategic direction and develop innovative ways to create value. However, even though the idea of "renewal" and "adaptation" can be seen from various perspectives, focus of strategic agility are for various factors and strengths; including new ideas, technology, socio-economic variables, and various organizations and non-government in them.

Strategic agility provides the ability to connect insights about the external business environment with internal capabilities and convert it into actions. According to [4], such organizations are built to be able to survive themselves. This kind of organization have an awareness, structure and process that keeps them alert, and adaptive.

Organizations that have strategic agility aware of environment changes and can respond to it quickly and, ultimately, determine their own future. They predict the future and allocate significant resources for future development so that they can maintain their sustainable competitive advantage. They operate in capacities that are more than just survival: they lead in their own markets. Continuous self-renewal is a way of life for these organizations and their members. 
Strategic agility consists of three capabilities, such as strategic sensitivity, collective commitment, and resource fluidity [4]. All three capabilities must support each other to achieve success, we cannot choose only one capability, but it must have a combination of the three capabilities. If collective commitment is not supported by the ability to move resources from a business unit because the individual motives and the main objectives of the business unit are not aligned, then strategic agility will have a negative impact [4].

[4] characterize Strategic Agility consists of three main capabilities: (1) Strategic sensitivity, includes the focus of the organization's attention and the level of intensity in which the company perceives and interprets the reality of market conditions (2) Collective Commitment, how company management can makes quick and right decisions and without take organizational politics as consideration , (3) Resource Fluidity, the ability to adjust and renew business system and relocate resources quickly according to needs and circumstances. They argue that innovation and constant development of new capabilities are the only sources of excellence for sustainable competitiveness.

The first ability in strategic agility is strategic sensitivity which is defined as the ability to predict markets and become a leader in the industry [4]. Many previous studies presented this capability, because this ability is the basis for subsequent strategic decision-making and action. Usually it takes a long time for the organization to realize the need for change. The environment often provides some sign of change, but many organizations are not alert and ready to make changes if the signs of change have not been felt strongly [5]. Therefore organizations must have a higher level of awareness, sustainable awareness including honest and open strategic discussions among leaders, managers, and other stakeholders, so that there will be different opinions and inputs in an effort to make changes further [4].

Strategic sensitivity depends on accepting and analyzing various types of information to understand the environment to decide on effective actions [6]. Reading the environment effectively, analyzing and managing market information, and understanding the market environment are very important in order to be flexible and achieve success. Strategic senitivity is very important to create a shared vision among leaders. Collaborating with consumers enables leaders to increase market needs and strategic sensitivity.

Collective commitment requires managerial leadership to work together in making important decisions and avoiding political conflict and self-interest. [4] The faster leaders can make important decisions, the faster organizations can take advantage of opportunities [7]. Establishing strong shared goals strengthens trust among leaders for more committed and united teams [8].

Looked at how organizations with organizational leaders work together, especially in developing markets, achieving the possibility of success, especially when operating quickly. Speed, conflict, and cooperation allow the organization's leadership team to create effective strategies in a dynamic environment and ambiguity [9]. Furthermore, he also noted that formulating simple rules increased the ability of the organization's leadership team to act fast based on overall market knowledge. The importance of healthy market understanding to plan proactively in anticipating potential environmental turbulence [10].

Resource fluidity is the organization's internal ability to relocate resources quickly to capture opportunities and distance themselves from failures [4]. Examples of resources that move toward opportunities arise in several studies. [11] propose resource fulidity to create and manage adaptive and anticipatory flexibility. Furthermore, [12] ambitious organizations control flexible, varied and easy-to-use resources that allow flexibility. The ability to move resources to opportunity areas is very important to create competitive advantage [4]. 


\subsection{Environmental Turbulence}

Environmental turbulence is defined as environmental conditions with high level of uncertainty and risk. Environmental turbulence is an important construction that captures volatility in the corporate environment. Environmental turbulence is made up of a competitive business environment and risks that come up from the company, and the complexity and heterogeneity of the supply chain. Tan et al. (1999) suggest a environment turbulence that is conceptualized in terms of the time and resources that needed to compete with the competitors.

Uncertainty produce risks faced by companies. For example, the more uncertain the customer demand is, the greater risk of running out of stock and the excess stock faced by the company. Lee (2002) classifies the supply chain in terms of supply and demand uncertainty. The uncertainty of demand is due to the short product life cycle, the number of product types, the seasonal nature of the product, demand and high obsolescence costs. In other hand, technological uncertainty will also cause product age faster than the time it should. [13] categorizes uncertainty based on three levels of the supply chain planning hierarchy: strategic, tactical and operational.

Environmental turbulence is also characterized by uncertainties arising from unexpected changes in market demand, consumer preferences, new technological developments, and technological breakthroughs [14]. They found that in a turbulent environment there are three types of capabilities that will produce strategic advantage such as: (1) operational (the ability to carry out processes), (2) dynamic (planned capabilities to reconfigure operational capabilities), and (3) improvisational (the learned ability to spontaneously reconfigure operational capabilities). The last two abilities can be seen as dynamic capabilities in general. Therefore, there is a relationship between dynamic ability and competitive advantage in a turbulence environment.

\subsection{Competitive Advantage}

Competitive advantage is one of famous studies in modern strategic theory. Competitive advantage is a keyword in organizational space as the main method for creating a successful business. Some scholars have focused on the relationship between competitive advantage and organization success. However, it is hard to determine and measure competitive advantage [15]. [16] notice that it is important for managers to use analytics to understand internal and external environments of the organization. Linking business models to identify competitive advantage enables managers to identify areas of differentiation to achieve competitive advantage [16]. A typical measure for analyzing the effectiveness of competitive advantage is performance.

The creation of competitive advantage consists of inter-relationships within organizations on technology, innovation, human resources, and overall organizational structure [17]. [18] defines competitive strategies as the company's efforts to create positive competitive positions in certain industries. The aim of developing competitive positions is to create profitable longterm positions through the application of three general strategies (cost, differentiation, and focus). Developing a competitive position to create competitive advantage is the basis of several modern seminal theories.

[19] argues organization can be different among other competitors if they have a competitive advantage as the organization's distinctive competencies, thus giving them a place in the marketplace. These differences must relate to some product/service attributes which is the key buying criteria for the customer. Key buying criteria are variables and criteria that customers use while making their purchase decisions. The key buying criteria are different 
between industries, and between market segments. Competitive advantage is an advantage gained over competitors by offering customers greater value, either through lower prices or by providing additional benefits and services that justify similar or possibly higher prices. A competitive advantage is meaningful if it is related to attributes valued by the market. Some examples of such attributes are product quality, price and after-sales service. Competitive advantages can be created through first mover advantage, environmental adaptation, new ideas, operating efficiency, quality, and customer responsiveness.

The creation of competitiveness excellence consists of inter-relationships within organizations on technology, innovation, human resources, and overall organizational structure. [18] defines competitive strategies as organizational efforts to create positive competitive positions in certain industries. The aim of developing competitive positions is to create profitable long-term positions through the application of three general strategies (cost, differentiation, and focus). Developing a competitive position to create competitive advantage is the basis of several modern seminal theories.

Competitiveness is one of the most important topics in strategic management. [20] Sustainable competitive advantage as a source of sustained superior performance of organizations. The advantage of competitiveness itself is the comparison of the relative performance of an organization among its competitors in the product market [21].

Using a structural approach, [18] suggests an industry analysis framework (five forces) that explains profit sustainability through the interaction between bargaining power in a particular industry. While [21] defines an organization that has competitive advantage as an organization that can produce more economic value than competitors. Economic value is the difference in perceptions of value seen by customers with actual economic costs for buying products or services.

In order to have a sustainable competitive advantage, organizations must have resources that meet the following attributes: valuable, rare, imperfect, and irreplaceable. [20] Resources include tangible assets, and intangible assets, for example: assets, capabilities, competencies, organizational processes, attributes, information, and knowledge possessed by the organization. The four attributes of the resource are suggested by assuming that the resource market is heterogeneous and does not move to make it a 'durable' advantage [21].

\subsection{Organizational Performance}

Although the concept of organizational performance is very common in the academic literature, to define it is difficult because of it has many meanings. Because of that, there isn't a universally accepted definition of organizational performance. Achieving the success of strategy implementation, according to [22], is when the organization called to have a successful performance.

Provide a set of definitions the concept of organizational performance:

- Performance has an indicator of a set of financial and nonfinancial within offer information on the degree of achievement of objectives and results [23], [24].

- Performance is dynamic, requiring judgment and interpretation.

- Performance may be illustrated by using a causal model that describes the future result that affected by current actions.

- Performance may be understood differently depending on the person who involved in the assessment of the organizational performance (e.g. performance can be understood differently from a person within the organization compared to one from outside).

- To define the concept of performance is necessary to know its elements characteristic to each area of responsibility. 
- To report an organization's performance level, it is necessary to be able to quantify the results.

\section{Hypotheses}

Agility consists of three main capabilities: (1) Strategic sensitivity includes the focus of the organization's attention and the level of intensity in which the company perceives and interprets the reality of market conditions (2) Collective Commitment is how company management makes quick and brave decisions without limited by organizational politics, (3) Resource Fluidity is the ability to adjust business systems and relocate resources quickly according to needs and circumstances. They argue that innovation and constant development of new capabilities are the only sources of excellence in sustainable competitiveness.

Hypotheses 1: Strategic agility has positive impact on competitive advantage.

It has been established that in the environmental turbulence condition organizations should have the value chain engage in collective action to reduce the impact of environmental turbulence [25]. Therefore, firms with a greater level of strategic agility, having greater level of re-configurability and market acuity. If organization could arise competitive advantage they would show better achievement of competitive operations capabilities and competitive financial performance as they will be able to better adapt and more flexible adjust to the fastchanging environment compared to their competitors. This happens as the strategically agile firms can reconfigure their resources to fit the requirements of emerging change better according to the literature off strategic agility dimensions (strategic sensitivity, collective commitment, and resource fluidity

Dynamic capability of strategic agility will help the firms with strategic option to exploit the opportunities and aware of the threats as they emerge [26]. The greater the environmental turbulence the more will be the beneficial effect of strategic agility [27]. The reverse scenario will emerge if the environmental turbulence is low as there will be no added value in being strategically agile because the exploitation of existing competencies will lead to better results [28]. Thus, it appears that environmental turbulence would impact on strategic firm agility on competitive advantage and financial performance of a firm. Therefore, the proposed hypothesis is:

Hypotheses 2: Environmental Turbulence has positive impact on strategic Agility.

Competitive advantage has been so popular in strategic studies, but it reveals that though the subject has received substantial attention, in most empirical studies it is not measured directly. On the contrary, performance indicators such as profit, productivities, etc are used as proxies. [29] addresses the differences between a firm's performance, and competitive advantage. This separation can also hela to have a better understanding of how competitive advantage relate to performance, and how this relationship enhances performance of the organization [30].

[31] found that even though there is a lot of literature about the interaction of competitive advantage and organizational topic but the relationship between competitive advantages and performance in has been insufficiently explained and much research in strategy literatures tend toward speculation.

Literature on competitive advantage in many industries in terms of customer-based dimensions of retention, satisfaction, and growth rather than in financial terms. Accordingly, it is suspected that developing competitive advantages will help organization to make a better satisfy customers relative to rivals. Indeed, the dynamic capabilities examined here enable firms to sense and seize on any opportunities and reconfigure/transform resources to address 
market needs. Thus, based on the literature performance will rise as a result of developing competitive advantages:

Competitive Advantage refers to competition as a result of the obtainable scheme of the company [32]. Organization that can arise competitive advantage when they can outperform better than any other rivals. [33] are purposes that the organization have to utilize of the competition by looking for an opportunities and awareness of threat for the best support operations to perform exceed the competitors. [34] refers to the value of strategy which helps the companies succeed in performing businesses and achieve excellence operations and companies' improvement. By this result, the following hypothesis is:

Hypotheses 3: Competitive advantage has positive impact on strategic Agility.

The next section outlines the research design and methodology of this research.

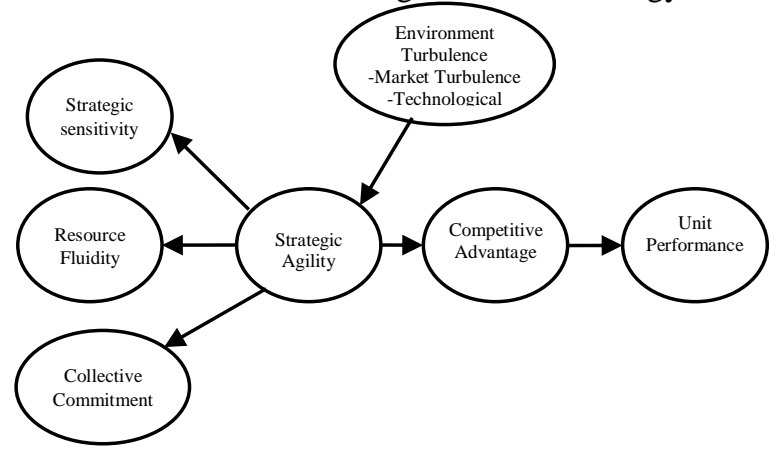

Fig. 1. Structural Model.

\section{Method}

The main objective of this study is to empirically investigate the mediating roles of competitive advantage on the relationship between strategic agility and performance in the turbulence environment. To analyze the hypotheses above, this research conducted at one of private bank in Indonesia, using 41 samples from the manager levels. We use questionnaire consist 48 items with Likert scale indicator from 1 (strongly disagree) to 6 (strongly agree). The use of scale 1 to 6 is aimed to avoid the tendency of respondents choosing neither agree or disagree in order to speed up the time of filling questionnaire.

Measurement was taken from previous studies. Strategic agility was measured with 19 indicators that represent strategic sensitivity, collective commitment and resource fluidity from [35]. Environmental turbulence was measured with ten indicators that represent market turbulence and technological turbulence, from [36]. Competitive advantage five indicators that represent from [36]. Unit Performance were measured with eight indicators that represent productivity, growth, satisfying rate, and reputation from [35].

\section{Result}

Sample of this study consisted of $15 \%$ female and $85 \%$ male respondent; with the average age of the respondent was between below 30 and above 50 in the second place. Majority level of respondent education was Bachelor, and majority of the number of subordinate in their unit is up to 10 people. The details demography of the participants is presented on Table 1 below. 
Table 1. Demography Data.

\begin{tabular}{|c|c|c|}
\hline Criteria & Count & $\begin{array}{l}\text { Percentage } \\
(\%)\end{array}$ \\
\hline \multicolumn{3}{|l|}{ Gender } \\
\hline Male & 35 & 85 \\
\hline Female & 6 & 15 \\
\hline \multicolumn{3}{|l|}{ Age } \\
\hline$\leq 30$ & 14 & 34 \\
\hline $31-40$ & 10 & 24 \\
\hline $41-50$ & 4 & 10 \\
\hline$>50$ & 13 & 32 \\
\hline \multicolumn{3}{|l|}{ Education } \\
\hline $\mathrm{S} 1$ & 26 & 63 \\
\hline $\mathrm{S} 2$ & 14 & 34 \\
\hline S3 & 1 & 3 \\
\hline \multicolumn{3}{|l|}{ Tenure } \\
\hline $0-4$ & 12 & 29 \\
\hline $5-10$ & 13 & 31 \\
\hline $11-20$ & 4 & 10 \\
\hline$>20$ & 12 & 30 \\
\hline \multicolumn{2}{|l|}{ Number of } & 27 \\
\hline$<5$ & 11 & 27 \\
\hline $5-10$ & 19 & 46 \\
\hline$>10$ & & \\
\hline
\end{tabular}

To analyze the research data, various analyses are used. Such as convergent and divergent validity and coefficient of correlation between variables of the research are examined. Then, to examine the validity of the question we can use confirmatory analysis. I use PLS to test the hypotheses.

Table 2 consist of item to show validity and reliability of the research. For Cronbach's Alpha has normally value above 0.7 to ensure convergent validity. The values obtained show the convergent validity CR (strategic agility) $=\frac{(0.910+0.871+0.851)^{2}}{(0.910+0.871+0.851)^{2}+(0.171+0.241+0.275)^{2}}=0.936$ of the measurement instrument is acceptable. Composite Reliability coefficients are also above 0.7 , supporting the appropriate fit of the measurement models. For the second-order latent variable "strategic agility, CR, and AVE are calculated as follows 
Convergent validity is tested with AVE variables and it shown in the table, all of variable's AVE is above 0.5 After confirming validity and reliability of measures of the constructs, the reukt of the structural model ae evaluated, which shows how latent variables are connected to each other.

In the table 3, will show the overall effect of the exogenous constructs is indicated on unit performance and other latent variables.

Table 2. Validity and Reliability Indicators.

\begin{tabular}{|l|c|c|c|c|c|}
\hline & AVE & $\begin{array}{c}\text { Composite } \\
\text { Reliability }\end{array}$ & R Squared & $\begin{array}{c}\text { Cronbach's } \\
\text { Alpha }\end{array}$ & Shared Value \\
\hline Strategic Agility & 0.504 & 0.934 & 0.663 & 0.924 & \\
\hline Strategic Sensitivity & 0.513 & 0.513 & 0.828 & 0.766 & \\
\hline Collective Commitment & 0.512 & 0.878 & 0.758 & 0.836 & \\
\hline Resource Fluidity & 0.691 & 0.87 & 0.724 & 0.775 & \\
\hline Environmental Turbulence & 0.532 & 0.898 & 0 & 0.869 & \\
\hline Competitive Advantage & 0.581 & 0.873 & 0.639 & 0.82 & \\
\hline Unit Performance & 0.601 & 0.922 & 0.509 & 0.903 & \\
\hline
\end{tabular}

Table 3. Significance Test of Structural Model Results.

\begin{tabular}{|l|r|r|r|r|}
\hline \multicolumn{1}{|c|}{ Path } & \multicolumn{1}{|c|}{$\begin{array}{c}\text { Path } \\
\text { Coefficient }\end{array}$} & t-values & $\begin{array}{c}\text { Error } \\
\text { Probability }\end{array}$ & $\begin{array}{c}\text { Significanc } \\
\text { e }\end{array}$ \\
\hline Strategic Agility -> Strategic Sensitivity & 0.91 & 26.203 & $0.000 \%$ & $\mathrm{P}<0.01$ \\
\hline Strategic Agility -> Collective Commitment & 0.871 & 16.343 & $0.000 \%$ & $\mathrm{P}<0.01$ \\
\hline Strategic Agility -> Resource Fluidity & 0.851 & 13.966 & $0.000 \%$ & $\mathrm{P}<0.01$ \\
\hline Strategic Agility -> Competitive Advantage & 0.799 & 11.506 & $0.000 \%$ & $\mathrm{P}<0.01$ \\
\hline $\begin{array}{l}\text { Environmental Turbulence -> Strategic } \\
\text { Agility }\end{array}$ & 0.814 & 12.194 & $0.000 \%$ & $\mathrm{P}<0.01$ \\
\hline $\begin{array}{l}\text { Competitive Advantage -> Unit } \\
\text { Performance }\end{array}$ & 0.714 & 8.844 & $0.000 \%$ & $\mathrm{P}<0.01$ \\
\hline
\end{tabular}




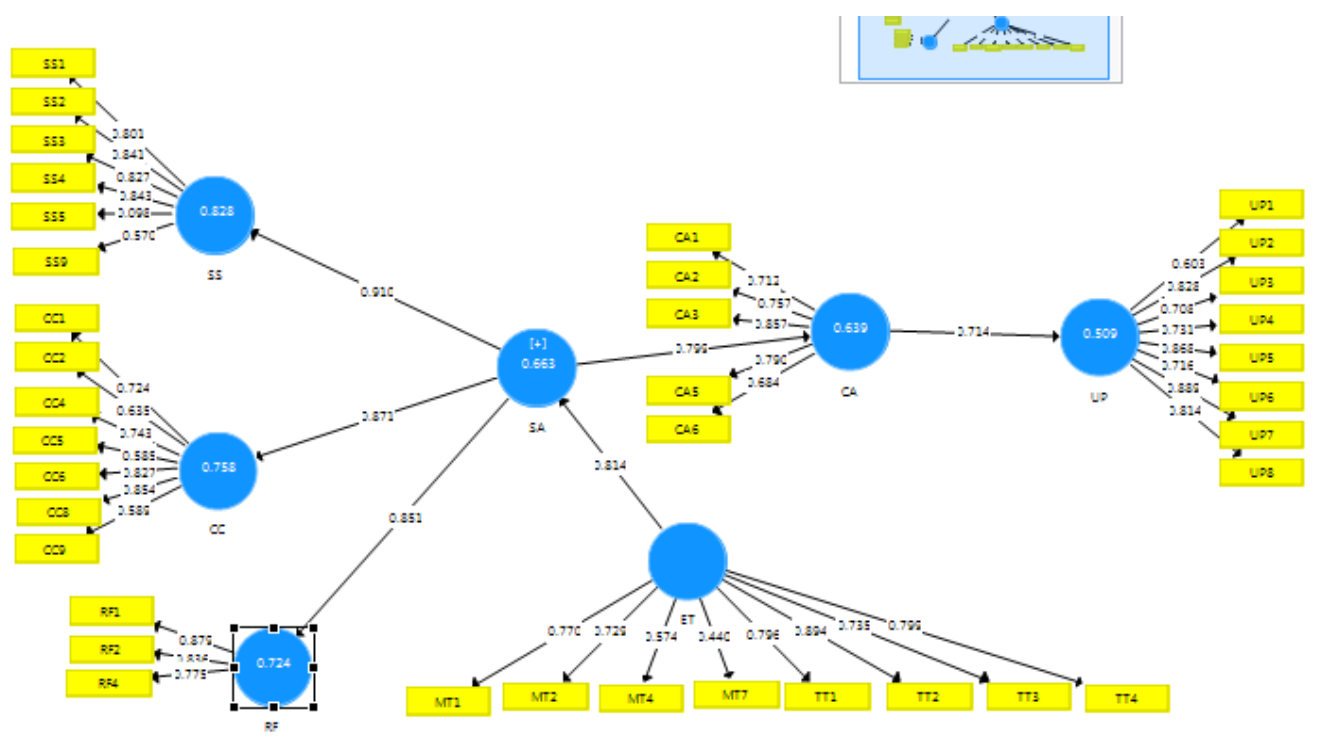

Fig. 2. SEM in the Case Path Coefficient.

Table 3 confirms the relationship between constructs of the model and hypotheses of the research are supported. As data of table show, all of hypotheses has a relationship with the level of confidence $90 \%$.

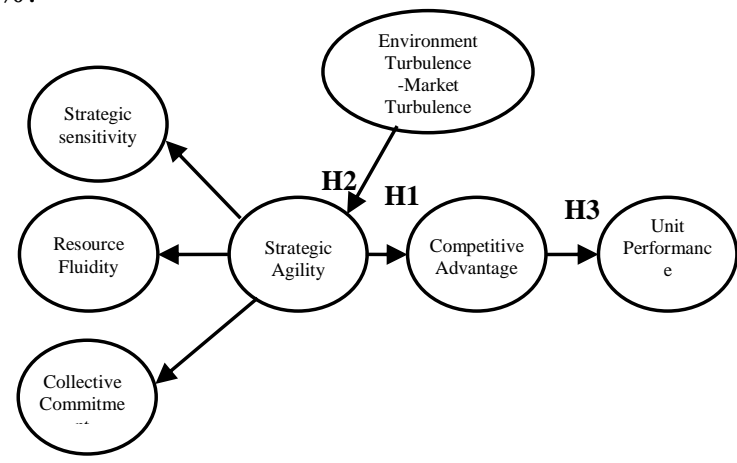

Fig. 3. Hypotheses Result (T-Value).

\section{Discussion and Conclusion}

The main purpose of the present research was to analyze the causal role of strategic agility to competitive advantage in order to enhance unit performance in environmental turbulence and determine its dimensions. For this purpose, general dimensions of strategic sensitivity, collective commitment, and resources fluidity were introduced as meta-capabilities of strategic agility [4].

Finding of the research show that respondents agree on the issue that the capabilities of strategic sensitivity, collective commitment, and resource fluidity is equivalent to capabilities in agility at the strategic level. Hence, hypotheses related to dimensions of strategic agility are supported. In other words, if a bank want to achieve competitive advantage in order to 
increase the unit performance, Bank must apply certain capabilities of the three dimensions of strategic agility that mentioned above.

The three meta-capabilities (strategic sensitivity, collective commitment, and resource fluidity) were statistically significant predictors of organizational performance. These findings supported [4] theory that all three meta-capabilities must be applied together to predict organizational performance.

The results of the study show that the most important dimension to achieve strategic agility is strategic sensitivity and the next rank belong to collective commitment and strategic sensitivity, even though all three capabilities must support each other to achieve success, we cannot choose only one capability, but it must have a combination of the three capabilities. If strategic sensitivity is not supported by the ability to move resources from a business unit because the individual motives and the main objectives of the business unit are not aligned, then strategic agility will have a negative impact [4].

\section{References}

[1] D. Grewal, G. R. Iyer, and M. Levy, "Internet retailing: Enablers, limiters and market consequences," J. Bus. Res., vol. 57, no. 7, pp. 703-713.

[2] D. M. Santos, B. Cao, A. Yazdanbakhsh, D. J. Norton, S. Neargarder, and A. CroninGolomb, "Perceptual, cognitive, and personality rigidity in Parkinson's disease," Neuropsychologia, vol. 69, pp. 183-193.

[3] K. T. Frith, H. Cheng, and P. Shaw, Race and beauty: A comparison of Asian and. Western.

[4] Y. Doz and M. Kosonen, Fast Strategy: How Strategic Agility Will Help You Stay Ahead of the Game. Philadelphia: Wharton School Publishing.

[5] J. P. Kotter, Leading Change. Boston: Harvard Business School Press.

[6] V. Fernandez-Perez, V. J. Garcia-Morales, and O. F. Bustinza-Sanchez, "The effects of CEOs' social networks on organizational performance through knowledge and strategic flexibility," Pers. Rev., vol. 41, no. 6, pp. 777-812.

[7] J. E. Schrager and A. Madansky, "Behavioral strategy: a foundational view," J. Strateg. Manag., vol. 6, no. 1, pp. 81-95.

[8] A. Franken and H. Thomsett, "When It Takes a Network: Creating Strategy and Agility through Wargaming," Calif. Manage. Rev., vol. 55, no. 3, pp. 107-133.

[9] M. Eisenhardt, "Top management teams and the performance of entrepreneurial firms," Small Bus. Econ., vol. 40, no. 4.

[10] K. Mason and S. Mouzas, "Flexible business models," Eur. J. Mark., vol. 46, no. 10, pp. 1340-1367.

[11] T. Busch and V. H. Hoffmann, "How hot is your bottom-line? Linking carbon and financial performance," Bus. Soc., vol. 50, no. 2, pp. 233-265.

[12] T. Reichert, J. Lambiase, S. Morgan, M. Carstarphen, and S. Zavoina, "Cheesecake and beefcake: No matter how you slice it, sexual explicitness in advertising continues to increase," Journal. Mass Commun. Q., vol. 76, pp. 7-20.

[13] Landeghem, "Rules for integrating fast changeover capabilities into new equipment design," in Robotics and Computer in Manufacturing, 8, pp. 3-4.

[14] P. A. Pavlou, E. Sawy, and O. A, "Understanding the Elusive Black Box of Dynamic Capabilities," Decis. Sci., vol. 42, no. 1.

[15] C. Sigalas and V. Pekka Economou, "Revisiting the concept of competitive advantage: Problems and fallacies arising from its conceptualization," J. Strateg. Manag., vol. 6, no. 1, pp. 61-80. 
[16] Blackwell and M. Eppler, "Understanding and Managing Conversations from a Knowledge Perspective: An Analysis of the Roles and Rules of Face-to-face Conversations in Organization," Studies, vol. 29, pp. 1287-131.

[17] J. Liao, Wang, and L., "Face as a mediator of the relationship between material value and brand consciousness," Psychol. Mark., vol. 26, no. 11, pp. 987-1001.

[18] M. E. Porter, Competitive Strategy: Techniques for Analyzing Industries and Competitors. New York: Free Press.

[19] A. A. Thatte, "Competitive advantage of a Firm Through Supply Chain Responsiveness and Supply Chain Management Practices." .

[20] J. B. Barney, Gaining and sustaining competitive advantage. Addision-Wesley: Reading, MA.

[21] J. Barney and W. S. Hesterly, Strategic Management and Competitive Advantage: Concepts and Cases. Upper Saddle. River, New Jersey: Pearson/Prentice Hall.

[22] N. Venkataraman, "Strategic Orientation of Business Enterprises: The Construct, Dimensionality, and," Meas. Manag. Sci., vol. 35, no. 8, pp. 942-962.

[23] M. Lebans and K. Euske, A conceptual and operational delineation of performance. Business Performance Measurement, Cambridge University Press.

[24] R. Kaplan, Norton, and D., "The Balanced Scorecard-Measures That Drive Performance," Harv. Bus. Rev., vol. 79.

[25] X. Chen, "Impact of Business Intelligence and IT Infrastructure Flexibility on Competitive Advantage: An Organizational Agility Perspective. Dissertations and Theses from the College of Business Administration.".

[26] B. Kogut and U. Zander, "Knowledge of the Firm, Combinative Capabilities, and the Replication of," Technol. Organ. Sci., vol. 3, pp. 383-397.

[27] V. Sambamurthy, A. Bharadwaj, and V. Grover, "Shaping Agility through Digital Options: Reconceptualizing the Role of," Inf. Technol. Contemp. Firms. MIS Q., vol. 27.

[28] D. Leonard-Barton, "Core capabilities and core rigidities: A paradox in managing new product development," Strateg. Manag. J., vol. 13, pp. 111-125.

[29] T. Powell, "Competitive advantage: logical and philosophical considerations," Strateg. Manag. J., vol. 22, no. 9, pp. 875-888.

[30] D. Chadee and R. Kumar, "Sustaining the international competitive advantage of Asian firms: A conceptual framework and research propositions," Asian Pacific J. Manag., vol. 18, pp. 461-480.

[31] A. Kaleka, "When exporting manufacturers compete on the basis of service: resources and marketing capabilities driving service advantage and performance." .

[32] E. R. Wagner, "Eric N. Hansen," Manag. Decis., vol. 43, no. 6, pp. 837-850.

[33] S. Tien, Y. Chung, and C. Tsai, "An empirical study on the correlation between environmental design implementation and Business competitive advantages in Taiwan's industries," Technovation, vol. 25, pp. 783-794.

[34] F. Navarro, A. V Bacurau, and S. S. Aimeida, "Exercise prevents the effects of experimental arthritis on the metabolism and function of immune cells," Cell Biochem Funct, vol. 28, no. 4, p. 273.

[35] D. G. Oventhal, Stuck in neutral: The effect of strategic agility within the U.S. powersports industry. Capella University.

[36] S. Haynes and C. A.H, "How \#me too is taking a life of its own in Asia," Time Mag. 